\title{
Memórias portuárias em disputa: (re)leituras do Porto Maravilha
}

\author{
JORGE DE LA BARRE \\ Universidade Federal Fluminense, Rio de Janeiro, Rio de Janeiro, Brasil \\ KARIME PEREIRA RIBEIRO DE LIMA \\ Universidade do Estado do Rio de Janeiro, Rio de Janeiro, Rio de Janeiro, Brasil \\ DOI 10.11606/issn.2316-9133.v28i1p227-248
}

resumo Iniciado em 2011 pelo então Prefeito Eduardo Paes, o projeto Porto Maravilha representa até hoje um dos empreendimentos mais emblemáticos do processo de revitalização urbana ocorrido no Rio de Janeiro. Este artigo pretende explorar os discursos oficiais e não-oficiais no contexto da dupla agenda carioca de megaeventos esportivos (2014 e 2016) - mais particularmente as diversas formas de reinterpretação do significado da herança africana na região. A partir do trabalho de campo, o artigo explora as narrativas e os embates associados a três lugares de memória oficialmente reconhecidos pelo órgão de comunicação do projeto Porto Maravilha no âmbito do recém-criado "Circuito Histórico e Arqueológico de Celebração da Herança Africana”: o Centro Cultural José Bonifácio, o Armazém Docas Pedro II e o Instituto dos Pretos Novos.

palavras-chave Herança Africana; Lugares de memória; Projeto Porto Maravilha; Renovação urbana; Rio de Janeiro.

\section{Port memories in dispute: (re)readings of Rio's Porto Maravilha}

abstract Initiated in 2011 by then Mayor Eduardo Paes, the Porto Maravilha project represents to this day one of the most emblematic projects of the urban revitalization process in Rio de Janeiro. This article intends to explore the official and unofficial discourses in the context of Rio's double agenda of sports mega-events (2014 and 2016) - more particularly the different ways of reinterpreting the meaning of the African heritage in the region. From the fieldwork, the article explores the narratives and clashes associated with three places of memory officially recognized by the communication body of the Porto Maravilha project within the 
recently created "Historical and Archaeological Circuit of Celebration of African Heritage": the

Centro Cultural José Bonifácio, the Armazém Docas Pedro II, and the Instituto dos Pretos Novos.

Keywords African Heritage; Places of Memory; Project Porto Maravilha; Rio de Janeiro, Urban Renewal.

\section{Introdução}

A função da memória não é de lembrar, é de esquecer.

-Luiz Alfredo Garcia Roza

Os projetos de reordenamento urbano da cidade do Rio de Janeiro na ocasião das obras do projeto Porto Maravilha revelaram muito além dos achados arqueológicos das escavações. Emergiram, pois, diferentes narrativas que buscavam orientar os desdobramentos da intervenção estatal na região portuária. A reivindicação do reconhecimento de outras memórias e matrizes culturais que compõem a região e a sociedade brasileira como um todo se deu em diversos campos de disputa: no âmbito das políticas públicas e patrimoniais, no seio dos movimentos sociais, e também no meio acadêmico e universitário.

No campo da história e das ciências sociais, a emergência de "memórias subterrâneas" (POLLAK, 1989; 1992) constitui um tema bastante fecundo. Os historiadores Eric Hobsbawm e Terence Ranger (1984) propuseram a ideia de que, em tempos de mudanças profundas, a “invenção das tradições” seria a garantia para uma certa estabilidade. Gilberto Velho (2006) indicou por seu lado que a existência ou o reconhecimento do patrimônio pressupõem a negociação e o conflito. Também Simone Vassalo (2012) sugeriu que o imaginário relacionado a uma necessidade de modernização traz consigo o desejo de se preservar alguns locais escolhidos como vestígios do passado.

No contexto carioca, a tentativa de definição da existência de uma "outra" memória foi conduzida por diferentes forças e processos. No âmbito da recente transformação da região portuária, observamos a existência de disputas entre diversos discursos na (re)constituição da memória. Em A utopia da Pequena África, Roberta Sampaio Guimarães (2014) mostrou que a valorização da contribuição africana para a região e sua história foi significativamente “acelerada” pelos empreendimentos relativos ao projeto Porto Maravilha e, pelo que nos parece, a região portuária passou também por uma reinvenção da sua tradição (BROUDEHOUX; MONTEIRO, 2017) com a criação do "Circuito Histórico e Arqueológico de Celebração da Herança Africana”. 
É necessário um olhar sociológico e etnográfico sobre a produção do discurso oficial, e sobre a produção do espaço. A pesquisa se concentrou em uma análise crítica dessas formas de produção na região portuária no contexto atual do projeto Porto Maravilha, tentando caracterizar as temáticas e formas de legitimação utilizadas, assim como as narrativas e contranarrativas em jogo, a própria visibilidade in situ do projeto Porto Maravilha e suas interações com o tecido urbano e sociocultural da região.

Assim, recolhemos informações relativas ao projeto Porto Maravilha divulgadas em sites oficiais, imprensa, blogs, e identificamos os vários discursos. Todo o conteúdo foi analisado posteriormente e identificado conforme as chaves: narrativas oficiais ou contra-discursos, imagens oficiais ou contra-imagens, usos ou "contra-usos" (LEITE, 2002) dos vários espaços da região portuária. Assumimos como oficial o material produzido e divulgado em sites oficiais do projeto, e como não-oficial aquele recolhido por nós através de entrevistas e da análise de conteúdo de blogs que mantiveram uma postura crítica em relação ao projeto.

Pretendíamos também documentar os lugares e territórios envolvendo a produção de uma imagem atualizada da região portuária. A observação direta dos lugares e territórios urbanos permitiu uma caracterização conforme as duas dimensões principais: herança histórica e/ou gentrification, "enobrecimento" (ZUKIN, 2000), requalificação urbana contemporânea. Enfim, levantamos e analisamos criticamente a coexistência de narrativas e de espaços na região portuária no contexto do projeto Porto Maravilha. Os resultados permitiram identificar vários tipos de uso dos lugares e territórios, e uma caracterização dos mesmos a partir da distinção entre lugares de história e lugares de memória. Esses discursos e contra-discursos, usos e contrausos foram confrontados à experiência urbana contemporânea no Rio de Janeiro, e sua paisagem real e imaginária.

Para realizar a pesquisa retratada no presente artigo, foi necessário combinar diferentes metodologias. Em um primeiro momento, nos baseamos em uma análise documental do conteúdo divulgado sobre o projeto Porto Maravilha, realizada a partir dos veículos oficiais de comunicação da Prefeitura do Rio de Janeiro - a CDURP (Companhia de Desenvolvimento Urbano da Região do Porto do Rio de Janeiro) -, e da concessionária Porto Novo S/A. Buscamos por documentos oficiais referentes às transformações urbanas: decretos, portarias e notas no Diário Oficial, tanto como matérias e notícias jornalísticas (PORTO MARAVILHA; "Porto Maravilha e a Pequena África", REVISTA PORTO MARAVILHA; VISIT.RIO).

Além da análise documental, a pesquisa incluiu um levantamento bibliográfico, visitas à região e entrevistas abertas com interlocutores dos quais nos aproximamos ao final do primeiro semestre de 2018. A pesquisa bibliográfica foi responsável por nortear o que procuramos encontrar nas visitas a campo. Os trabalhos encontrados focavam sobre o empreendimento, as reformas e alterações urbanas do projeto Porto Maravilha, ou sobre a sociabilidade, a memória e a influência negra no patrimônio e na cultura locais; nos detivemos mais nesse segundo aspeto. 
Começamos, então, a utilizar o método etnográfico com pequenas incursões aos espaços "recriados". Além de visitar os pontos da região que compõem o Circuito Histórico e Arqueológico de Celebração da Herança Africana, acompanhamos visitas guiadas realizadas pelos pesquisadores do Instituto dos Pretos Novos junto com o Museu de Arte do Rio. No 22 de novembro de 2017, acompanhamos também um trabalho de campo da turma de "História da Cultura do Rio de Janeiro”, sob supervisão da professora da Universidade Federal Fluminense, Martha Abreu.

Queríamos ouvir sobretudo a narrativa pouco visibilizada dos ativistas, dos moradores e dos movimentos sociais da região. Por isso entrevistamos o fotógrafo Maurício Hora, uma funcionária do Centro Cultural José Bonifácio (CCJB), o guia do Circuito Histórico e Arqueológico de Celebração da Herança Africana do Instituto dos Pretos Novos (IPN), dois representantes da ONG "Ação da Cidadania”, assim como a professora Martha Abreu e o professor Cezar Honorato. Esses interlocutores nos ajudaram a entender as dinâmicas em jogo e os contra-discursos produzidos, no contexto das transformações urbanas levantadas pelo Porto Maravilha. As entrevistas foram abertas e de duração variável dependendo do entrevistado.

O presente artigo está dividido em quatro partes. A primeira parte apresenta a região portuária no momento atual da sua transformação. A segunda parte trata da criação do Circuito Histórico e Arqueológico de Celebração da Herança Africana, no contexto do projeto Porto Maravilha. A terceira parte discute alguns aspetos teóricos da relação entre memória, história e identidade. Finalmente, apresentamos a partir da perspectiva dos interlocutores entrevistados, os embates em jogo em três lugares de memória da região portuária: o Centro Cultura José Bonifácio, o Armazém Docas Pedro II e o Instituto dos Pretos Novos.

\section{A região portuária e o Porto Maravilha}

De maneira indiscutível, estudar o projeto Porto Maravilha é desnaturalizar o porto e as atividades que o cercam e ter em mente que elas se renovam à medida que a sociedade se renova. A atividade portuária molda as relações econômicas e sociais das regiões que se inserem, desde o comércio até as sociabilidades dos seus habitantes; é igualmente moldada pelas especificidades de sua localização geográfica e pelo momento histórico. No presente momento, a região portuária do Rio de Janeiro passa por uma série de transformações que têm um impacto profundo em diferentes dimensões da vida dos seus habitantes e frequentadores. As transformações em curso no âmbito do projeto Porto Maravilha não são apenas urbanísticas e arquitetônicas, mas também simbólicas, culturais e sociais. Notadamente, a geografia da região se transformou radicalmente na véspera do Jogos Olímpicos de 2016.

Desde a derrubada da Perimetral entre a Praça XV e a Estação Rodoviária, assistimos às aberturas da "nova" Praça Mauá e seus museus - o Museu de Arte do Rio e o Museu do Amanhã 
-, à transformação da Avenida Rodrigues Alves em "Boulevard Olímpico", às aberturas do AquaRio, da Orla Conde, do Túnel Rio 450 Anos, e à inauguração do VLT (Veículo Leve sobre Trilhos) entre o Aeroporto Santos Dumont e a Estação Rodoviária Novo Rio. Por um lado, a "nova” Praça Mauá se tornou ícone global da revitalização do Porto Maravilha; por outro, a Praça da Harmonia, com seu coreto tombado e a Rua Pedro Ernesto ao lado onde se encontram o Cemitério dos Pretos Novos e o CCJB, permanece um centro popular dos bairros Saúde/Gamboa que entrou num processo de transformação com sua recente estação de VLT, e um hipotético projeto de transformar futuramente o Moinho Fluminense em shopping.

Nos processos de transformação e renovação urbanas atuais, a "figura" do megaevento (esportivo ou não) torna-se um paradigma: uma forma de "solucionismo" (MOROZOV, 2013; LA BARRE, 2013) aplicado à cidade como um todo, capaz de resolver "todos os problemas", realizando quase magicamente, acredita-se, uma espécie de ajusto estrutural instantâneo. Inevitavelmente espetaculares, as transformações urbanas em curso levam um custo social não menos importante. Lembremos por exemplo da construção do Teleférico do Morro da Providência entre a Estação Central e a Vila Olímpica da Gamboa, cuja consequência foi a remoção de inúmeros moradores da região. Apesar dos discursos oficiais sobre o empreendimento vendido como "progresso", as tentativas de organização e resistência locais não foram atendidas (SÁNCHEZ et al., 2016). Emblemáticas de uma "arquitetura de poder" (ZUKIN, 2000), as transformações atuais são as mais visíveis. Tal como a ponte de um iceberg, no entanto, elas vão revelando as forças de uma história mais antiga, agora em fase de ressignificação no âmbito do projeto de revitalização urbana ainda em curso na região portuária.

A região portuária pode ser entendida a partir das noções de coexistência e de fronteiras simbólicas. Trata-se de uma região que condensa comunidades com vivências históricas e vividas muito distintas: das comunidades quilombolas (CORRÊA, 2016), a moradores da região desde há gerações (SCHWOB, 2012), com um movimento associativo significativo (COSTA, 2011). Observamos ainda as várias formas de reinterpretação e instrumentalização da memória no contexto da revitalização atual (PORTO MARAVILHA, 2011; "Rio’s Legacy Has Began”, 2011; RODRIGUES, 2013). A questão da patrimonialização, através da criação de um Circuito histórico e arqueológico (BRAGA, s.d.), semelhante ao Corredor cultural do Centro (LIMA, 2007; SANTANA, 2011), coexiste hoje com o ambicioso projeto Porto Maravilha, cuja espetacularização durante a Olimpíada de 2016 atraiu milhares de cariocas e turistas. A poucos metros da festa olímpica, no entanto, vimos que a pobreza, violência e exclusão permaneceram como se nada tivesse acontecido na realidade cotidiana dos milhares de moradores da região.

Uma ênfase relevante é a questão da patrimonialização e/ ou espetacularização dos espaços requalificados, e as lutas político-simbólicas associadas. Existe uma literatura extensa sobre a questão (JEUDY, 2005; JEUDY; JACQUES, 2006; LEITE, 2002, 2009; LEITE; PEIXOTO, 2008; ZUKIN, 2000, 2008) e, mais especificamente sobre a região portuária do Rio de Janeiro - uma 
região das mais antigas que, de Pereira Passos a Eduardo Paes, viu desfilar vários prefeitos com seus projetos de revitalização (DINIZ, s.d.). A questão das disputas territoriais é também importante (GUIMARÃES, 2008; 2013; 2014; NASCIMENTO, 2014; NASCIMENTO; SILVA, 2015). Hoje, com as narrativas em voga da cultura urbana - cidade global, cidade sustentável, sensível, resiliente, ou criativa -, o Rio de Janeiro entrou com grande pompa na arena das "cidades commodities"(MELLO, 2010), e o projeto Porto Maravilha é seu maior brasão (SARUE, 2015; LOPES; FRAGALLE, 2016). No entanto, além dos novos usos assim promovidos ou das tentativas de atrair novos públicos (“Turista é bom negócio”, PORTO MARAVILHA, 2017), a guerra de narrativas em jogo lembra que pelo menos algumas dúvidas permanecem (PORTO MARAVILHA PARA QUEM?).

\section{O Circuito histórico e arqueológico de celebração da herança africana}

Estabelecido pelo Decreto Municipal no 34.803 de 29 de novembro de 2011, o Circuito Histórico e Arqueológico de Celebração da Herança Africana foi criado pela CDURP (Companhia de Desenvolvimento Urbano da Região do Porto do Rio de Janeiro) - órgão oficial de comunicação do projeto Porto Maravilha -, no contexto das alterações urbanas produzidas pelo projeto Porto Maravilha. O Circuito demarca seis pontos, cada um deles remetendo a uma dimensão da vida dos africanos escravizados e seus descendentes na região portuária. São eles: o Cais do Valongo e o Cais da Imperatriz, a Pedra do Sal, o Largo do Depósito, o Jardim Suspenso do Valongo, o Cemitério dos Pretos Novos e o Centro Cultural José Bonifácio (Figura 1). Além do Circuito, notamos também o aplicativo "Passados Presentes", desenvolvido em 2016 pelas historiadoras Hebe Mattos e Martha Abreu.

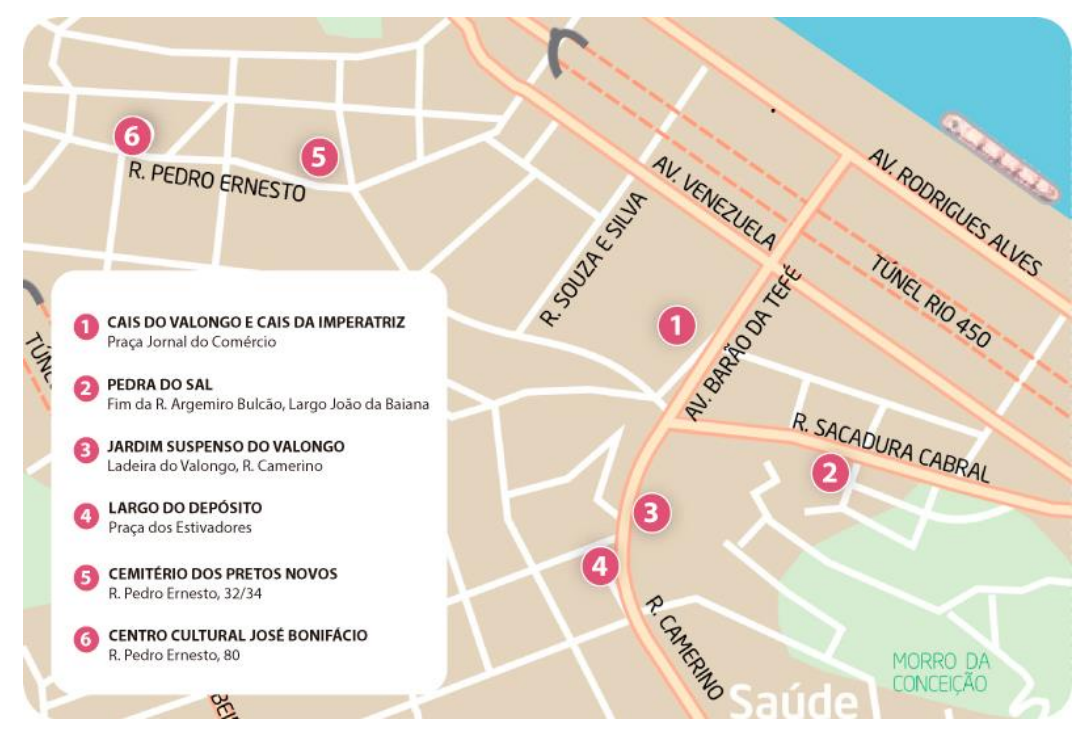


Figura 1. Mapa da região portuária com os seis pontos do Circuito Histórico e Arqueológico de Celebração da Herança Africana. Fonte: http://portomaravilha.com.br/circuito (acesso em 25 jan. 2019).

A criação do Circuito por parte da Prefeitura do Rio de Janeiro sugere que o reconhecimento de lugares de memória afro-brasileira está em curso. Tal reconhecimento evidencia a consonância com o cenário internacional como, por exemplo, as escolhas pela UNESCO: do ano de 2011 como Ano Internacional de Afrodescendentes, e da década 2015-2024 como Década Internacional de Afrodescendentes. Visto o aumento do número de eventos e comemorações, e a criação de órgãos diretamente relacionados à temática, observamos também no cenário nacional, uma aproximação com políticas de reconhecimento e tombamento de locais de memória afro-brasileira - por parte do governo federal em primeiro lugar, e por outros níveis de governo em segundo lugar.

Observamos um certo interesse acadêmico, cultural, político e social pela história da região e pelas atividades desenvolvidas recentemente. A região que se tornou foco de políticas culturais, patrimoniais e de planejamento urbano, foi um dos principais pontos da rota internacional do tráfico de escravos e palco de compra e venda de africanos escravizados. Por outro lado, uma certa conflitualidade está visível entre movimentos sociais e órgãos e representantes públicos. Ouvimos de muitos interlocutores a ideia de que, sem a organização dos movimentos sociais e a pressão política feita em torno das demandas de reconhecimento e reparação, muito pouco teria sido realizado, devido à falta de vontade política por parte dos governantes.

No momento presente, o projeto Porto Maravilha é o maior exemplo do modelo de concessão chamado Parceria Público-Privada (PPP). A PPP permitiu que a Prefeitura do Rio orientasse o prisma sob qual a revitalização/requalificação urbana da região portuária estaria alicerçada, e também quais recursos narrativos seriam privilegiados. De fato, os conceitos de revitalização e de requalificação representam um conjunto de ideias e ações que vão muito além da modernização dos equipamentos urbanos. Eles implicam também diretamente na ressignificação de uma área oficialmente encarada como "degradada" (OPERAÇÃO URBANA PORTO MARAVILHA, s.d.), fora dos padrões desejados. Estamos a todo momento diante de processos que ressignificam, isto é, dotam algo ou alguém de novos significados. Nesse contexto, as divergências conceituais são também divergências políticas.

A partir disso, assumimos que a criação do Circuito Histórico e Arqueológico de Celebração da Herança Africana parece resultar de uma configuração em que foi possível aos movimentos sociais, principalmente o movimento negro, pleitear o reconhecimento de pontos da região como lugares de memória afro-brasileira. Cada ator social identificado mobiliza sua memória e concepção própria da história na construção de seu discurso, influenciando sua forma 
de se posicionar social e politicamente. Todavia, quando estamos diante de um ator cujos discursos e ações são dotados de oficialidade, podemos observar tentativas de orientação da memória coletiva e dos lugares. Através da CDURP, a Prefeitura do Rio de Janeiro assumiu a criação oficial do Circuito Histórico e Arqueológico da Celebração da Herança Africana, constituído por seis pontos de interesse na região. No entanto, os outros atores - movimentos culturais, movimentos negros, movimento quilombola da Pedra do Sal - buscaram o reconhecimento de mais pontos representativos da herança africana da região.

O estigma da escravidão foi amplamente colocado. Durante nossas conversas, os interlocutores ressaltaram a luta contra o esquecimento de uma parte central da história brasileira, o sofrimento, a espoliação da população negra, e sua significação não menos central por parte dos movimentos sociais, notadamente o movimento negro. A "significação" aqui se refere à disputa simbólica pelo reconhecimento da herança cultural e identitária dos africanos escravizados e seus descendentes, bem como a sobrevivência material e imaterial de tal herança, e as identidades associadas. Conforme as lutas pelo reconhecimento e seu sucesso, certos lugares de história se tornam lugares de memória.

A rede acadêmica criada pelas historiadoras Hebe Mattos e Martha Abreu compreende uma forma distinta de pensar a herança africana, e propõe o reconhecimento de outras narrativas. As percepções do grupo de pesquisadores que estava envolvido com o "Inventário dos Lugares de Memória do Tráfico Atlântico de Escravos e da História dos Africanos Escravizados no Brasil" ", orientaram a seleção de 100 lugares de história na região, susceptíveis de ganharem o estatuto de lugares de memória em consonância com a reavaliação do legado e dos direitos dos afrodescendentes no Brasil e com a comemoração do ano de 2011 escolhido pela UNESCO como ano internacional dos Afrodescendentes. A rede tecida foi assim fortalecida por entidades internacionais e suas indicações.

As pesquisadoras Hebe Mattos e Martha Abreu também trabalharam em projetos sobre Memórias da Escravidão, conjuntamente com o representante do Brasil no Projeto "Rota do Escravo” da UNESCO, o antropólogo Milton Guran (MATTOS; ABREU; GURAN, 2013; 2014). A partir da elaboração de filmes historiográficos e material de divulgação audiovisual em parceria com o Laboratório de História Oral e Imagem (LABHOI/UFF), foi produzido o documentário "Passados Presentes: memória negra no sul fluminense" $(2011)^{2}$ sobre a trajetória, a memória e o patrimônio cultural dos descendentes dos últimos escravos da antiga província do Rio de Janeiro. Os principais eixos narrativos do documentário abordavam as "relações entre

\footnotetext{
${ }^{1}$ Inventário realizado em 2013 pelo Laboratório de História Oral e Imagem da UFF (LABHOI/UFF), em parceria com a UNESCO (Projeto "Rota do Escravo"). Disponível em: http://www.labhoi.uff.br/sites/default/files/inventario_julho_2013.pdf. Acesso em 05 set.2018.

2 Disponível em: http://ufftube.uff.br/video/3D39427215O2/Passados-Presentes--mem\%C3\%B3ria-negra-no-sulfluminense. Acesso em 05 set. 2018.
} 
memória, escravidão e formas de pertencimento e cidadania (...) bem como as releituras políticas de memória da escravidão no tempo presente e a memória da escravidão enquanto presença do passado nas trajetórias de vida de libertos e seus descendentes." 3

O documentário deu origem ao aplicativo para celular do mesmo nome: "Passados Presentes". Conforme as idealizadoras, trata-se de "uma plataforma de divulgação científica, mas também de informações para o turismo comunitário e de memória, bem como poderosa ferramenta didática para o ensino da história da África e da cultura afro-brasileira.” Pelo aplicativo, o usuário vai "passeando" pela história da região e consultando informações sobre os pontos identificados. O aplicativo funciona como um guia que identifica alguns pontos de memória, e como alguns desses pontos não existem mais no mundo real, o aplicativo representa também uma forma de preservação da memória no mundo virtual.

Podemos notar então a dupla mobilização do conceito de memória. Em primeiro lugar, com base na criação do Circuito, a memória é convocada no âmbito de intervenções reais no espaço urbano, por parte da Prefeitura do Rio de Janeiro. Em segundo lugar, com a realização do aplicativo, a memória é projetada e pode ser virtualmente acessada. A realização dos dois projetos foi analisada com seus diversos pontos respectivos, que refletem discursos, práticas e novos sentidos distintos, e sugerem também uma produção diferenciada, à volta da cidade, da região portuária e do conceito de memória.

\section{Memória, história e identidade}

A construção de narrativas bem como de identidades no espaço urbano pressupõe a mobilização do conceito de memória. De fato, memória, história e identidade, são conceitos que atravessam o espírito do Circuito Histórico e Arqueológico da Celebração da Herança Africana, e do aplicativo "Passados Presentes". As contribuições de autores como Maurice Halbwachs, Michael Pollak e Pierre Nora parecem aqui fundamentais.

Halbwachs, sociólogo pertencente à escola de Durkheim, é pioneiro em suas formulações acerca da memória coletiva (HALBWACHS, 1950). Afirmava ele que toda memória se estrutura em identidades de grupos e que as recordações dos indivíduos são essencialmente memórias de grupo e que a memória do indivíduo é um produto provavelmente único de determinada intersecção de grupos. Para Halbwachs, a problemática da memória girava em torno da sua transmissão e ramificação em memória coletiva e memória histórica/individual. $\mathrm{O}$ uso do conceito de memória difere em decorrência de quem o mobiliza. Nele, está contida também a ideia do tempo, que se difere conforme o uso e quem o usa, mas que podemos entender de duas formas que se encontram, mas não se confundem: o tempo cronológico e o tempo de memória.

\footnotetext{
3 Texto introdutório do eixo temático “Memória, África, Escravidão” do LABHOI. Disponível em: http://www.labhoi.uff.br/escravidao. Acesso em 15 jun. 2019.
} 
O tempo cronológico é utilizado para embasar pesquisas e intervenções de arqueólogos e historiadores; é mobilizado em estudos de reconhecimento, por exemplo. Já o tempo de memória pertence aos moradores de uma região, é o tempo da experiência vivida. A memória de uma região não é estéril: dela partem os movimentos sociais, seus discursos. Suas colocações e ações são orientadas a partir de concepções próprias da memória.

No início de seu artigo "Memória, esquecimento, silêncio”, Michael Pollak (1989) relembra Halbwachs: "Em sua análise da memória coletiva, Maurice Halbwachs enfatiza a força dos diferentes pontos de referência que estruturam nossa memória e que a inserem na memória da coletividade a que pertencemos" (POLLAK, 1989, p. 3). Em outro artigo, "Memória e identidade social”, Pollak (1992) coloca que a memória é um elemento constituinte do sentimento de identidade, tanto individual como coletiva, na medida em que ela é central no sentimento de continuidade e de coerência de uma pessoa ou de um grupo, na reconstrução de si. Pollak introduz nesse artigo o conceito de "trabalho de enquadramento da memória", que visa por exemplo a formação de uma história nacional.

A contribuição de Pierre Nora reside na distinção entre memória e história e no reconhecimento das questões relacionadas aos lugares, onde a memória se cristaliza e se refugia. Nos "lugares de memória”, existe uma interação entre memória e história:

Os lugares de memória são, antes de tudo, restos. [...] São os rituais de uma sociedade sem ritual; sacralizações passageiras numa sociedade que dessacraliza; fidelidades particulares de uma sociedade que aplaina os particularismos; diferenciações efetivas numa sociedade que nivela por princípio; sinais de reconhecimento e de pertencimento de grupo numa sociedade que só tende a reconhecer indivíduos iguais e idênticos. (NORA, 1993, p. 12-13).

Tais lugares são simultaneamente materiais, simbólicos e funcionais. Ao conceituar os "lugares de memória", Nora busca expor o jogo que supõe uma "vontade ou intenção de memória", isto é, o componente político que diferencia os "lugares de memória" dos "lugares de história" - aqueles que não foram "dignos" de lembrança. Por exemplo, o conceito de "lugares primeiros" se refere às localizações que poderão ser tomadas por aqueles que, conforme as suas identidades sociais, se veem relacionados com os mesmos. Temos ainda a ideia de que apenas certos grupos ou indivíduos seriam lembrados, ao detrimento de outros. Como afirma Nora, os lugares de memória são "sinais de reconhecimento e de pertencimento de grupo numa sociedade que só tende a reconhecer indivíduos idênticos” (NORA, 1993, p. 13). No entanto, Ana Paula Goulart Ribeiro destaca, "os sujeitos só lembram a partir do ponto de vista de um grupo social específico, ao qual de alguma forma se vinculam: a memória está interligada diretamente às 
identidades sociais." (RIBEIRO, 2003, p.3). Observamos de fato uma mobilização de tais conceitos nos processos de reformas urbanas que visam ressignificar a cidade. Enquanto a categoria de "ressignificação", ela

[...] passa a designar processos sociais por meio dos quais semânticas sociais - rubricas que a sociedade usa para sua autodescrição - são alteradas documentalmente no contexto de ações políticas coletivas. Essa releitura faz com que ressignificação deixe de abranger processos identitários, mas permite que ela ganhe em alcance sociológico, pois ela permite perceber que a narrativa do tempo histórico está não apenas permanentemente em aberto, está também sempre em disputa. (BACHUR, 2017, p. 10-11).

Se o objetivo comunicacional da CDURP é "vender" o projeto Porto Maravilha e fazer que ele seja recebido de forma positiva pela opinião pública, isto não quer dizer que a narrativa produzida seja a única (a versão oficial é apenas uma versão entre outras), e nada garante que todos os atores sociais em jogo estejam aderindo a tal produção de legitimação do projeto. Os discursos de renovação, requalificação, revitalização, etc., são também, literalmente, discursos de ressignificação: produzem retóricas performativas, narrativas programáticas, e projetam um futuro próximo desejado no presente. Enquanto projeto de renovação urbana, o Porto Maravilha implica também uma narrativa de renovação que vai se utilizar dos recursos simbólicos da história, do passado e da memória, instrumentalizando-os para seus fins de promoção.

Introduziremos, na próxima seção, algumas situações conflitivas observadas durante os segundo semestre de 2017 e primeiro de 2018, tais como: as tentativas de criação de um novo museu com o nome provisório de Museu da Escravidão e da Liberdade (MEL); as disputas judiciais pela instauração do MEL no Armazém Docas Pedro II, ocupado pela ONG "Ação da Cidadania”; o baixo repasse de recursos aos equipamentos culturais já existentes frente aos recém-criados Museu de Arte do Rio e Museu do Amanhã; o veto do atual prefeito pelo tombamento da Pedra do Sal como patrimônio imaterial da cidade; a alteração da data da "lavagem" da mesma Pedra do Sal, considerada sagrada para grupos religiosos de matriz africana. Assim, como nos lembra Michael Pollak, "Essa predileção atual dos pesquisadores pelos conflitos e disputas em detrimento dos fatores de continuidade e de estabilidade deve ser relacionada com as verdadeiras batalhas da memória a que assistimos [...].” (POLLAK, 1989, p. 2).

\section{Quais lugares de memória? Narrativas em conflito}




\section{O Centro Cultural José Bonifácio}

Em visita ao Centro Cultural José Bonifácio (CCJB - Figura 2) - inserido no Circuito Histórico e Arqueológico da Celebração da Herança Africana -, conhecemos duas pessoas que foram importantes para elucidar alguns dos nossos questionamentos. A primeira, uma funcionária do CCJB que se aposentou logo então, e o segundo, um senhor que trabalha como guia do Instituto dos Pretos Novos com quem teremos em outra data uma longa e esclarecedora conversa - voltaremos a esse ponto.

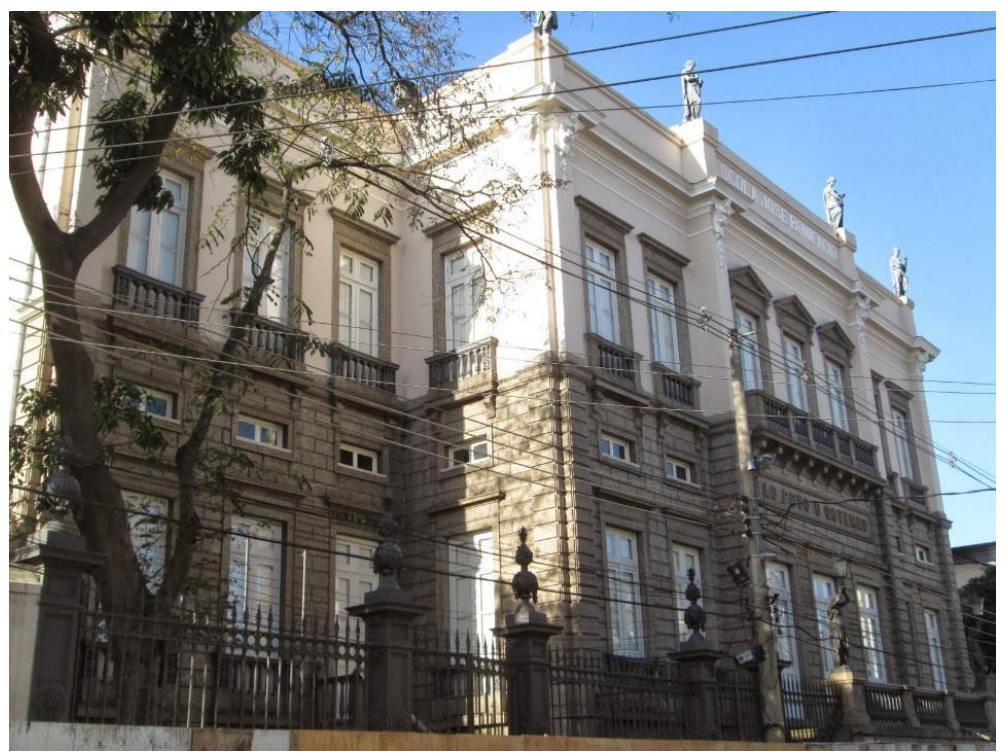

Figura 2. O Centro Cultural José Bonifácio.

Fonte: http://girocariocatour.blogspot.com/2013/11/centro-cultural-jose-bonifacio.html.

O CCJB é uma das primeiras escolas públicas primárias do Brasil, foi inaugurado em 1877; o nome homenageava o tutor de Dom Pedro II, José Bonifácio, que não foi um abolicionista em sua época. Mesmo assim nome foi mantido para o Centro Cultural, no entanto as salas foram batizadas com nomes de personalidades negras, entre elas Tia Ciata, Mestre Marçal e Madame Satã. Pudemos observar que apesar de seu valor histórico e simbólico ser compartilhado por especialistas, pesquisadores e ativistas, a população local pouco conhece o Centro, além de muitos apresentarem dúvida em relação ao seu funcionamento pois, recentemente, o prédio esteve fechado por um longo período para reformas.

Em visita às salas, notamos que a maioria delas estava vazia, à exceção de duas; uma ocupada por um ensaio de um conjunto de palhaçaria, a outra por uma exposição de quadros que retratavam personalidades negras conhecidas e desconhecidas, tendo inclusive uma pintura recente da vereadora assassinada Marielle Franco. Após a visita, pedimos que a nossa 
interlocutora falasse um pouco sobre as atividades que o espaço desenvolvia; ela nos contou que o CCJB estava em mais um momento de transição.

Naquele momento, a instituição contava com uma equipe de quatro funcionários apenas, que se dividiam entre as funções administrativas, recepção, visita guiada e segurança está contando com dois funcionários em turnos alternados. As atividades desenvolvidas no espaço ocorriam conforme a demanda para sediar eventos, palestras, cursos, ensaios e exposições ligadas ou não à temática afrodescendente. Além disso, o CCJB conta com uma pequena biblioteca que guarda um acervo voltado para essa temática, e faz parte de uma rede de instituições que promove ações com o intuito de capacitar profissionalmente e disseminar atividades culturais voltadas para a população negra.

\section{O Armazém Docas Pedro II}

Após ser reformado com recursos do Porto Maravilha, o CCJB abrigaria teoricamente eventos e exposições centrados na temática afrodescendente/afro-brasileira - o que não estava previsto era sua transformação em sede do Museu da Escravidão e da Liberdade (MEL). À época, os funcionários estavam aguardando o processo judicial em tramitação, em razão da disputa legal pela permanência ou saída do Armazém Docas Pedro II (Figura 3) da ONG “Ação da Cidadania”, movida pela Prefeitura do Rio de Janeiro. O que havia sido passado para a funcionária era que o MEL “englobaria” o CCJB e não o contrário.

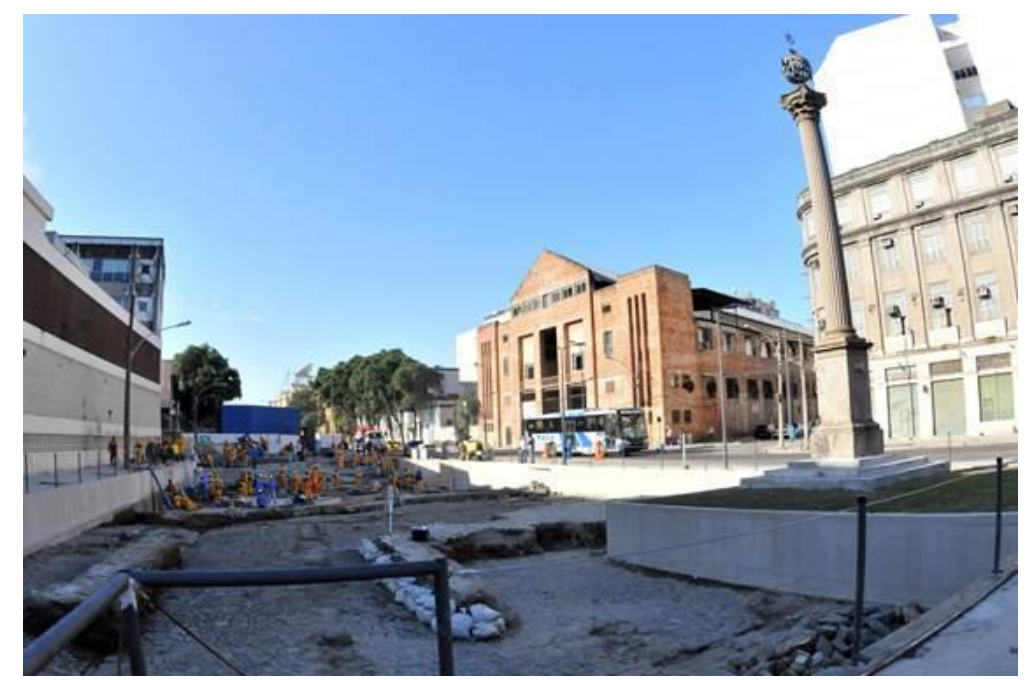

Figura 3. O Armazém Docas Pedro II, visto do Cais do Valongo.

Fonte: http://portomaravilha.com.br/noticiasdetalhe/3906.

Fomos, então, atrás de mais informações sobre o MEL. Considerando o atual momento econômico e político, sua criação é, no mínimo, conflituosa, devido à escassez de recursos para 
os equipamentos culturais do município, e sua distribuição desigual entre os museus novos (MdA, MAR) e os antigos - estes muitas vezes contando apenas com recursos para sua manutenção.

Nesse meio tempo, conhecemos uma representante da ONG "Ação da Cidadania" e, ao sermos apresentados, aproveitamos para perguntar se poderíamos conversar sobre o projeto Porto Maravilha, as implicações da criação do MEL e a possível alocação dele no Armazém Docas Pedro II ocupado há um tempo pela ONG. Alguns dias do nosso encontro, trocamos links de matérias recentes dos jornais $O$ Globo e $O$ Dia, sobre a ordem de despejo recebida, sem nem terem conhecimento da situação.

O nosso encontro foi no Armazém Docas Pedro II, que fica em frente ao Cais do Valongo. O imóvel é parte integrante do complexo do sítio arqueológico do Cais do Valongo, declarado Patrimônio da Humanidade em 2017, mas desde 2000 é ocupado pela ONG “Ação da Cidadania”, fundada pelo sociólogo e ativista Herbert de Souza, o Betinho. Lá conversamos por cerca de duas horas com a representante e um funcionário da ONG. Este, o mais antigo da organização, nos contou sobre os projetos desenvolvidos e as reformas feitas desde que a "Ação da Cidadania” ocupa o Armazém.

Segundo ele, o projeto de sede do MEL nos locais não se justifica, pois não há mais nenhum resquício da construção original do engenheiro afro-brasileiro André Rebouças, porque o Armazém teve de ser totalmente reconstruído por conta da deterioração e da falta de infraestrutura básica, rede de água e esgoto e fiação elétrica. Tanto ele quanto a representante especularam várias vezes que, se a ONG não estivesse ocupando o local, o mesmo muito provavelmente não teria resistido às obras feitas na região e em seu lugar haveria um grande prédio de vidro.

Orientamos, então, a conversa para as matérias jornalísticas que incitavam um aparente conflito: a Prefeitura do Rio tentara, pela segunda vez, desocupar o Armazém por meio de uma ação judicial. Contudo, o Armazém Docas Pedro II pertence ao governo federal e só pode ser desocupado por ele, estando a Prefeitura equivocada ao exigir tal desocupação sem o respaldo judicial de uma ação da União. Segundo a representante da ONG, o governo federal é favorável à sua manutenção, e está transferindo atualmente a posse para a Fundação Palmares (que também responde ao governo federal), para garantir o alvará de permanência definitivo da ONG.

O funcionário contou que os problemas com a Prefeitura começaram quando a atual Secretária de Cultura assumiu o cargo. A entrada da Secretária era encarada como promessa de boa gestão na área cultural, devido ao período que ela esteve à frente do Museu do Cartola, popularmente conhecido como Museu do Samba. Aparentemente, ela foi convidada pela equipe do atual Prefeito por ser uma aliada em potencial, tendo em vista sua boa relação com os representantes culturais ligados ao samba. 
Ainda durante a conversa com os dois representantes da ONG, ouvimos que, no passado, houve a tentativa de criar um Centro de Referência da Diáspora Africana no Armazém, por iniciativa própria da "Ação da Cidadania". No entanto, o projeto não foi para frente, segundo eles por divergências com o movimento negro. O cerne das divergências com o movimento negro tenha a ver com a localização e o uso do espaço utilizado atualmente pela ONG. Para alguns ativistas do movimento negro, é precisamente por essa região ter um sentido sagrado os antepassados trazidos ao Brasil para serem escravizados estão enterrados ali -, que o local deveria ter outro uso. Outra divergência é suscitada pela falta de apoio à criação de um Memorial da Diáspora Africana da autoria deles, ou do Museu da Escravidão e da Liberdade pela Prefeitura.

Questionamos, então, quais seriam os grupos pertencentes ao movimento negro da região, mas eles não levantaram movimentos específicos, alegando que a temática estaria mais relacionada com o quilombo e com o Instituto dos Pretos Novos. No entanto, há, segundo eles, uma grande participação de lideranças comunitárias da região dentro da "Ação da Cidadania", porque a ONG oferece cursos de capacitação voltados à área social, sendo principal o serviço de distribuição de alimentos.

Sobre as disputas de interesses na desocupação do Armazém e a possibilidade do sítio arqueológico do Cais do Valongo perder o título de Patrimônio da UNESCO, foi mencionado que o "território" (isto é, a demarcação onde o Armazém se localiza) faz parte do sítio arqueológico, mas não a construção, por ter sido modificada. A permanência ou não da ONG não afetaria em nada o título de Patrimônio, e parece que a Prefeitura do Rio estaria focando nisso para desviar a atenção do que realmente faltou ser feito: a conservação do Cais do Valongo, cada dia mais erodido pela exposição aos elementos, e sem nenhuma placa de identificação ou cartaz turístico convidando a visitar o local. Logo, percebemos que na perspectiva dos nossos interlocutores, as tentativas de desocupação e a própria negação da importância do trabalho desenvolvido pela ONG são formas escusas que demonstram um interesse estratégico pelo espaço.

Para a obtenção do título de Patrimônio da Humanidade, o Brasil apresentou à UNESCO um dossiê de candidatura onde assumiu, entre diversos compromissos, a instalação de um "memorial da cultura de matriz africana" no local (o futuro MEL). Os compromissos assumidos devem ser cumpridos até o fim de 2019. Do contrário, o complexo do Cais do Valongo pode perder o título de Patrimônio da Humanidade. Até hoje a situação encontra-se num impasse, pois não foi decidido ainda se o espaço será compartilhado ou não.

$\mathrm{Na}$ audiência pública [do 8 de agosto de 2018], estavam presentes dezenas de integrantes da Ação da Cidadania e representantes de variadas entidades do movimento negro. Nos pronunciamentos, mostraram também as divergências entre os atores da sociedade civil. A posição do antropólogo 
Milton Guran, que coordenou a candidatura do Cais do Valongo, foi encampada por diversos ativistas negros. Ele defende que a presença da ONG no imóvel contraria o estabelecido no dossiê de candidatura. Para ele, o espaço deve abrigar exclusivamente um amplo museu. "Este espaço é essencial. Estamos falando do mais importante lugar de memória da diáspora africana no Ocidente. O Brasil tem o maior número de descendentes africanos fora da África”.

Por outro lado, o movimento negro também não se unifica em torno da proposta do MEL, elaborada pela prefeitura. Uma parte defende a ideia de um Memorial da Diáspora, que conte a história do tráfico de escravos, dê visibilidade aos seus desdobramentos e estabeleça diálogo com outros países envolvidos na diáspora africana.

A Ação da Cidadania diz não se opor a deixar o espaço, desde que seja oferecida uma alternativa razoável e um prazo que lhe permita planejar a mudança. A ONG afirma que não vê contradição com o movimento negro e lembra que o trabalho iniciado por Betinho em 1993 possibilitou a superação da fome por milhões de brasileiros, na sua maioria descendentes de africanos escravizados. "Entendemos a importância do espaço para a população negra e constantemente realizamos ações para lembrar o simbolismo do armazém, como a exposição e o musical de André Rebouças [engenheiro negro que construiu o Armazém Docas Dom Pedro II usando somente mão de obra de negros livres]”. (RODRIGUES, 2018).

\section{O Instituto dos Pretos Novos}

Após a conversa, continuamos o campo, agora em direção Instituto dos Pretos Novos (IPN - Figura 4), que se encontra em grandes dificuldades e ameaçado de fechar por falta de recursos (BORGES, 2018). Já havíamos nos encontrado algumas vezes com o guia do IPN responsável pelo percurso do Circuito de Herança Africana, inclusive no CCJB. Como havia pessoas conversando com ele sobre isso no momento que adentramos o espaço, aproveitamos o "gancho" para continuar o assunto. Primeiro, questionamos como estão sendo divulgadas as idas ao Circuito, pois o site do Porto Maravilha não é alimentado desde 2016 e, por isso, achamos que tivessem parado nesses dois anos. O guia nos disse que as idas ao Circuito só estavam sendo divulgadas no site do Porto Maravilha porque eles não tinham recursos para criar um site próprio do IPN e, tendo conseguido um financiamento, estão construindo uma página onde vão divulgar as atividades, incluindo as do Circuito, que, atualmente, tem como foco principal a sensibilização de crianças e adolescentes em passeios escolares. 


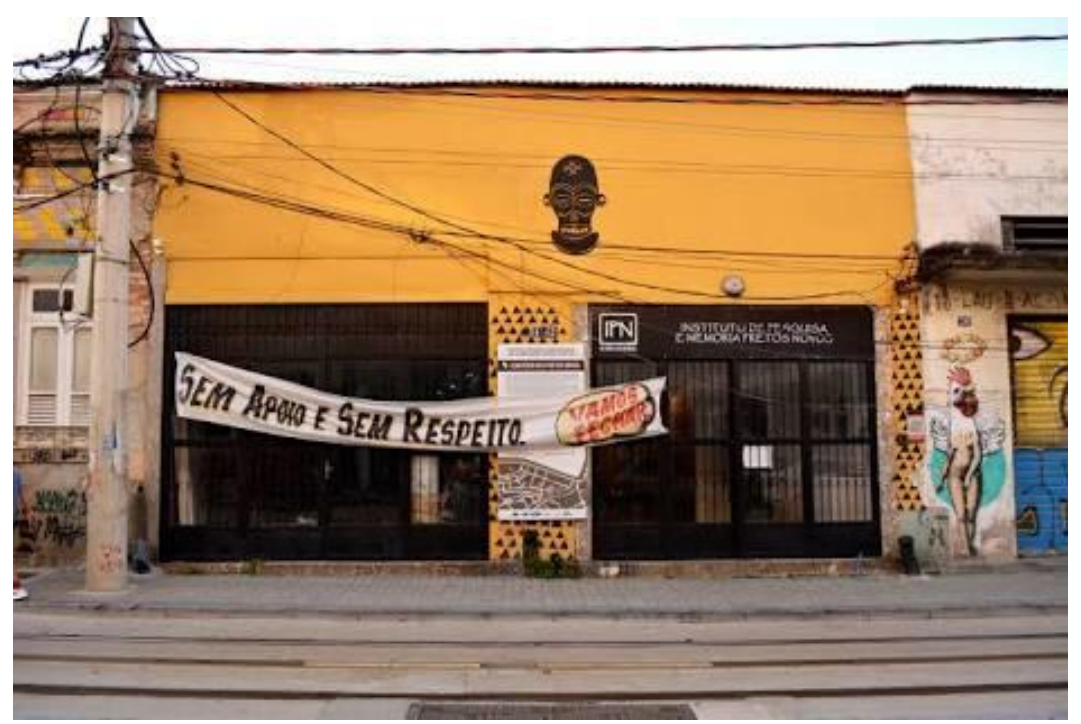

Figura 4. Fachada do Instituto do Pretos Novos.

Fonte: Retirado de: http://www.esquerdadiario.com.br/Porto-Maravilha-pra-quem-Semapoio-da-Prefeitura-Instituto-Pretos-Novos-luta-para-existir.

O guia tocou em um ponto crucial: de acordo com ele, a criação do Circuito foi uma demanda do IPN. Foram eles que reivindicaram o reconhecimento de um percurso que já faziam desde 2003, partindo da Praça XV até o IPN, e que a dificuldade de grandes grupos acompanharem o longo trajeto, muitas vezes debaixo do sol quente, fez com que surgisse a ideia da criação de um circuito com os pontos "principais". Ele comentou a existência de um Projeto de Lei anterior ao Decreto que instaura o Circuito que também versa sobre a valorização da memória afro-brasileira e o incentivo à visitação à região. O PL previa a criação de um monumento que teria a forma de arco para sinalizar a importância daquele local e tramitou na Câmara Municipal do Rio de Janeiro por algum tempo. Isso ressaltou a importância de enaltecer a memória na região e vinculá-la aos espaços escolhidos pela população local organizada.

Sobre os pontos do Circuito, o guia nos disse que, pela proeminência de sua localização, os Cais do Valongo e da Imperatriz eram indiscutivelmente essenciais, igualmente ao Cemitério dos Pretos Novos (que fica no IPN) e a Pedra do Sal, já reconhecida e tombada. O CCJB e o Largo do Depósito foram pontos levantados posteriormente à primeira manifestação do IPN para a criação do Circuito, enquanto o Jardim Suspenso do Valongo foi selecionado por um pesquisador e teve um parecer favorável pelo objetivo de valorizar a região que contava com muitos entulhos dos Morro da Conceição e do Valongo.

A memória é um lugar perigoso. -Luiz Alfredo Garcia Roza 


\section{Considerações Finais}

Com a exposição de parte de nosso percurso de pesquisa de 2017 a 2018, buscamos romper com a hipótese de uma rede de significações únicas e lançar luz ao movimento vívido da população da região portuária do Rio de Janeiro. As negociações entre o poder público e os movimentos sociais transpareceram e revelaram a existência de discursos e contra-discursos à volta da questão dos lugares de memória, entre outras. Contudo, a análise dos contra-discursos foi privilegiada neste trabalho, aproveitando a disponibilidade maior dos atores em nos receber e conceder entrevistas do que no caso dos representantes públicos oficiais. Tentamos fornecer um olhar entre diversos olhares possíveis sobre a região e os processos que a envolvem. Nossa inserção, nossos questionamentos sobre um objeto extremamente vivo nos fizeram acompanhar alguns desdobramentos, não no sentido de trazer respostas, mas sim de tentar compreendê-los.

De certa forma, a ressignificação do Brasil, do Rio de Janeiro e de sua região portuária na rota do tráfico de escravos aconteceu também no quadro do projeto Porto Maravilha. Os debates sobre herança, memória e lugares aconteceram também nos Museu de Arte do Rio e Museu do Amanhã - os dois atores institucionais mais novos da região. Nos deparamos de fato com uma região "reconstruída" do ponto de vista do planejamento urbano, e com grupos de atores que tiveram (e ainda têm) que se adaptar a novos espaços, desenvolvendo mecanismos de ação conjunta entre moradores e instituições. Como não poderiam deixar de ser, os debates permanecem extremamente vivos, sensíveis e polêmicos.

\section{Referências bibliográficas}

BACHUR, João Paulo. Política performativa e sociologia da ressignificação - reflexões a partir de Judith Butler. Anais do XVIII Congresso Brasileiro de Sociologia, Brasília/DF, 2017. Disponível em: http://www.adaltech.com.br/anais/sociologia2017/resumos/PDF-epostertrab-aceito-1549-1.pdf. Acesso em 26 jan. 2019.

BORGES, Domênica. Porto Maravilha pra quem? Sem apoio da Prefeitura Instituto Pretos Novos luta para existir. Esquerda Diário, 8 jan. 2018. Disponível em: http://www.esquerdadiario.com.br/Porto-Maravilha-pra-quem-Sem-apoio-da-PrefeituraInstituto-Pretos-Novos-luta-para-existir. Acesso em 26 jan. 2019.

BRAGA, Luciene. Prefeitura cria Circuito Histórico e Arqueológico da Celebração da Herança Africana. s.d. Disponível em: http://www.portomaravilha.com.br/upl oads/releases/55cbb33fb9a89.pdf. Acesso em 16 mar. 2017.

BROUDEHOUX, Anne-Marie; MONTEIRO, João Carlos. A reinvenção da zona portuária do Rio de Janeiro: estigmatização territorial, ressignificação simbólica e repovoamento planejado no projeto Porto Maravilha. Anais do XVII ENANPUR, São Paulo, 2017. 
CORRÊA, Maíra Leal. Quilombo Pedra do Sal. Belo Horizonte: FAFICH, 2016.

COSTA, Flávia Carolina da. "A revitalização da região portuária do Rio de Janeiro: política, associativismos e movimentos”. X Congreso Argentino de Antropología Social, XCAAS. Buenos Aires. La antropología interpelada: nuevas configuraciones político-culturales en América Latina, 2011.

DINIZ, Nelson. "De Pereira Passos ao projeto Porto Maravilha: colonialidade do saber e transformações urbanas da região portuária do Rio de Janeiro”. XII Colóquio Internacional de Geocrítica, s.d. Disponível em: http://www.ub.edu/geocrit/coloquio2012/actas/07-NDiniz.pdf. Acesso em 26 jan. 2019.

GUIMARÃES, Roberta Sampaio. Discursos de visibilidade e novos usos do território: o caso da Pedra do Sal (RJ). Anais do 32 Encontro Anual da ANPOCS, 2008. Disponível em:

https://www.anpocs.com/index.php/papers-32-encontro/gt-27/gt01-19/2264robertaguimaraes-discursos/file. Acesso em 26 jan. 2019.

A utopia da Pequena África. Os espaços do patrimônio na Zona Portuária carioca. Dissertação de Mestrado apresentada ao Programa de Pós-Graduação em Sociologia e Antropologia, Instituto de Filosofia e Ciências Sociais, Universidade Federal do Rio de Janeiro, 2011.

"Urban Interventions, Memories and Conflicts: black heritage and the revitalization of Rio de Janeiro's Port Zone”, Vibrant - Virtual Brazilian Anthropology, vol. 10, no. 1, January to June 2013. Brasília, ABA.

. A Utopia da Pequena África. Projetos Urbanísticos, Patrimônios e Conflitos na Região Portuária Carioca. Rio de Janeiro: FAPERJ/FGV Editora, 2014.

HALBWACHS, Maurice. A memória coletiva. São Paulo: Edições Vértice, 1990 (1950).

HOBSBAWM, Eric; RANGER, Terence (eds.). A invenção das tradições, Rio de Janeiro: Paz e Terra, 1984.

HONORATO, Cezar. Os afrodescendentes e a comunidade portuária do Rio de Janeiro do final do século XIX ao início do XX. Revista Crítica Histórica, no. 13, jun. 2016, p. 1-20.

JEUDY, Henri-Pierre. Espelho das cidades. Rio de Janeiro: Casa da Palavra, 2005.

JEUDY, Henri-Pierre ; JACQUES, Paola (orgs.). Corpos e cenários urbanos. Territórios urbanos e políticas culturais, Salvador: EdUFBA, 2006.

LA BARRE, Jorge de. Choque de futuro: o Rio dos megaeventos. O Social em Questão, Rio de Janeiro: Pontifícia Universidade Católica do Rio de Janeiro - PUC-Rio, Ano XVI, no. 29, vol. 1, 2013, p. 43-68.

LEITE, Rogério Proença. Contra-usos e espaço público: notas sobre a construção social dos lugares na Manguetown. Revista Brasileira de Ciências Sociais, vol. 17, n.49, 2002, p. 115-172. LEITE, Rogério Proença; PEIXOTO, Paulo, O patrimônio como elixir de políticas urbanas: Notas sobre o Bairro do Recife a Zona Histórica da Cidade do Porto. In: Anais da 26a Reunião 
Brasileira de Antropologia, 2008. Disponível em: http://www.abant.org.br/conteudo/NA AIS/CD_Virtual_26_RBA/grupos_de_trabalho/trabalhos/GT\%2013/O\%20PATRIM\%C3\% 94NIO\%20COMO\%20ELIXIR\%20DE\%20POL\%C3\%8DTICAS\%20URBANAS.pdf. Acesso em 16 mar. 2017.

LEITE, Rogério Proença. Cultura urbana contemporánea y el patrimonio ennoblecido”, Asociación Latinoamericana de Sociología, 2009. Disponível em: http://www.google.com. $\mathrm{br} / \mathrm{url}$ ?sa=t\&rct=j\&q=cultura\%20urbana\%20contempor\%C3\%A1nea\%20y\%20el\%20patrimo nio\%20ennoblecido\&source=web\&cd=1\&ved=0CC8QFjAA\&url=https\%3A\%2F\%2Fwww.s igaa.ufs.br\%2Fsigaa\%2FverProducao\%3FidProducao\%3D51180\%26key\%3D189cc0282ae2b 52aa1 fa1 cbde412199c\&ei=3N7NUY3wKtSj0QHxuIDQBg\&usg=AFQjCNEGdXGJQhZZ5P qgkYfnjHAmQzwDJg\&bvm=bv.48572450,d.dmQ. Acesso em 26 jan. 2019.

LIMA, Evelyn Furquim Werneck. Corredor cultural do Rio de Janeiro: uma visão teórica sobre as práticas da preservação do patrimônio cultural. Forum Patrimônio, vol. 1, no. 1, 2007, p. 78-91.

LOPES, Ruy Sardinha, e FRAGALLE, Natália Pauletto. Rio Criativo. O projeto Porto Maravilha em questão. e-metropolis, no. 26, ano 7, 2016, p. 15-24.

MATTOS, Hebe; ABREU, Martha; GURAN, Milton. Inventário dos Lugares de Memória do Tráfico Atlântico de Escravos e da História dos Africanos Escravizados no Brasil. Universidade Federal Fluminense: Laboratório de História Oral e Memória, 2013.

.Por uma história pública dos africanos escravizados no Brasil". Revista Estudos Históricos, vol. 27, no. 54, jun. 2014, p. 255-273.

MELLO, Marco Antonio da Silva. Cidades: commodities para consumo? (entrevista). Jornal da UFRJ, ano VI, n.53, 2010, p. 13-16. Disponível em: http://www.ufrj.br/docs/jornal/2010maio_JornalUFRJ53.pdf. Acesso em 26 jan. 2019.

MOROZOV, Evgeny. To Save Everything, Click Here. The Folly of Technological Solutionism. New York: PublicAffairs, 2013.

NASCIMENTO, Bruno Pereira. Disputas territoriais entre diferentes atores sociais e a reestruturação urbana. o caso da zona portuária do Rio de Janeiro. Anais do VII Congresso Brasileiro de Geógrafos, Vitória/ES, agosto 2014. Disponível em: http://www.cbg2014.agb.org.br/resources/anais/1/1404021474_ARQUIVO_ARTIGOCB G.pdf. Acesso em 26 jan. 2019.

NASCIMENTO, Bruno Pereira; SILVA, William Ribeiro. Zona portuária do Rio de Janeiro e suas novas territorialidades. Revista Geo UERJ, Rio de Janeiro, n. 26, 2015, p. 191-210.

NORA, Pierre. Entre memória e história: a problemática dos lugares. Projeto História, no. 10, 1993, p. 7-28. 
OPERAÇÃO URBANA PORTO MARAVILHA, s.d. Disponível em: http://www.portomaravilha.com.br/conteudo/portomaravilha/2018_livreto_geral.pdf?_t= 1532373289. Acesso em 14 jun. 2019.

POLLAK, Michael. Memória, esquecimento, silêncio. Estudos Históricos, vol. 2, no. 3, 1989, p. 3-15.

Memória e identidade social. Estudos Históricos, vol. 5, no. 10, 1992, p. 200-212, Disponível em: http://www.pgedf.ufpr.br/memoria\%20e\%20identidadesocial\%20A\%20c apraro\%202.pdf. Acesso em 26 jan. 2019.

PORTO MARAVILHA, Rio de Janeiro. Disponível em: http://www.portomaravilha.com.br/. Acesso em 26 jan. 2019.

PORTO MARAVILHA. “Turista é bom negócio”, 15 mar. 2017. Disponível em: http://portomaravilha.com.br/noticiasdetalhe/4656. Acesso em 26 jan. 2019.

Porto Maravilha e a Pequena África, Revista Inteligência Empresarial, Rio de Janeiro: CRIE / COPPE / UFRJ, no. 35, 2011.

PORTO MARAVILHA PARA QUEM? Espaço de discussão sobre a Área Portuária do Rio de Janeiro.

Disponível em: https://portomaravilhaparaquem.wordpress.com/. Acesso em 26 jan. 2019.

REVISTA Porto Maravilha, Rio de Janeiro. Disponível em: http://www.portomaravilha.com.br/revista . Acesso em 26 jan. 2019.

RIBEIRO, Ana Paula Goulart, "Memória de Jornalista: um estudo sobre o conceito de objetividade nos relatos dos homens de imprensa dos anos 50”. Compós, 2003. Disponível em: http://www.compos.org.br/data/biblioteca_712.pdf. Acesso em 26 jan. 2019.

"Rio's Legacy Has Began”. Rio Prefeitura, 2011. Disponível em: http://www.scribd.com/doc/130905694/Rio-s-Legacy-Has-Began. Acesso em 26 jan. 2019. RODRIGUES, Júlia Vilhena. Camadas de memória entre o Mar e o morro: da Pequena África ao Porto Maravilha. Brasília: Universidade de Brasília, 2013.

RODRIGUES, Léo. Audiência pública sobre o Cais do Valongo no Rio não encerra impasse. Agência Brasil, 8 ago. 2018. Disponível em: http://agenciabrasil.ebc.com .br/geral/noticia/2018-08/audiencia-publica-sobre-o-cais-do-valongo-no-rio-naoencerra-impasse. Acesso em 26 jan. 2019.

SÁNCHEZ, Fernanda, MOREIRA, Clarissa, SANTOS, Rosane, GROSSI, Grasiele, e GUTERMAN, Bruna. Possible Counter-Histories: Artivism and Popular Action in Morro da Providência, Rio de Janeiro. Streetnotes, n.25, 2016, p. 26-46.

SANTANA, Nara Maria Carlos de. "Memória, Políticas de Patrimônio e Turismo: o 'Corredor Cultural' no Rio de Janeiro”, Anais do XXVI Simpósio Nacional de História, ANPUH, São Paulo, julho de 2011. Disponível em: http://www.snh2011.anpuh.org/resou rces/anais/14/1308182702_ARQUIVO_TextoANPUH.pdf. Acesso em 26 jan. 2019. 
SARUE, Betina. Grandes projetos urbanos e a governança de metrópoles: o caso do Porto Maravilha no Rio de Janeiro. Dissertação (Mestrado em Ciência Política). São Paulo: Faculdade de Filosofia, Letras e Ciências Humanas, Universidade de São Paulo, 2015.

SCHWOB, Marcelo. Atrás do porto, uma cidade. Histórias da região portuária do Rio de Janeiro. Rio de Janeiro: Schwob, 2012,

VASSALLO, Simone. "Desenterrando memórias: uma análise das disputas em torno de sítios arqueológicos afrodescendentes na Zona Portuária do Rio de Janeiro”. Trabalho apresentado no $36^{\circ}$ Encontro Anual da ANPOCS, Caxambu, 2012. Disponível em: https://anpocs.com/index.php/encontros/papers/36-encontro-anual-da-anpocs/gt2/gt19-2/8062-desenterrando-memorias-uma-analise-das-disputas-em-torno-de-sitiosarqueologicos-afrodescendentes-na-zona-portuaria-do-rio-de-janeiro/file. Acesso em 26 jan. 2019.

VELHO, Gilberto. "Patrimônio, negociação e conflito". Mana, vol.12, n.1, 2006, p. 237-248.

VISIT.RIO. Disponível em: http://visit.rio/. Acesso em 26 jan. 2019.

ZUKIN, Sharon. "Paisagens urbanas pós-modernas: mapeando cultura e poder", in Arantes, Antônio Augusto (org.). O espaço da diferença. Campinas: Papirus, 2000. p. 80-115. “Consuming Authenticity”, Cultural Studies, vol. 22, no. 5, 2008, p. 724-748.

\section{autores}

\section{Jorge de La Barre}

Professor do Departamento de Sociologia e do Programa de PósGraduação em Sociologia da Universidade Federal Fluminense (GSOUFF, PPGS-UFF.

\section{Karime Pereira Ribeiro de Lima}

Mestranda em Ciência Política no Instituto de Estudos Sociais e Políticos da Universidade do Estado do Rio de Janeiro (IESP-UERJ). Foi bolsista do Programa de Iniciação Científica PIBIC/UFF, com projeto "Entre memória e esquecimento: leituras do Porto Maravilha”, sob orientação de Jorge de La Barre.

Recebido em 28/01/2019 Aceito para publicação em 16/06/2019 